\title{
PEMAHAMAN MASYARAKAT DAN PARA PEMANGKU KEPENTINGAN TERHADAP KONSEP TRANSIT ORIENTED DEVELOPMENT
}

\author{
Leonard Henry ${ }^{1}$ dan Leksmono Suryo Putranto \\ ${ }^{1}$ Program Studi Sarjana Teknik Sipil, Universitas Tarumanagara, Jl. Letjen S. Parman No.1 Jakarta \\ leonard.325150072@stu.untar.ac.id \\ ${ }^{2}$ Jurusan Teknik Sipil, Universitas Tarumanagara, Jl. Letjen S. Parman No.1 Jakarta \\ lexy_putranto@yahoo.co.id
}

Masuk: 16-01-2020, revisi: 13-05-2020, diterima untuk diterbitkan: 13-05-2020

\begin{abstract}
There are still many people who prefer to use private vehicles than to use public transportation. One way to reduce people's dependence on the use of private motorized vehicles is by applying the concept of Transit Oriented Development (TOD). But the application of the existing TOD concept is still not accordance with the actual concept so that the benefits of the TOD concept cannot optimally gained. Therefore, this study tries to review the level of understanding of students (Civil Engineering, Architecture, and Regional and City Planning), academics (Civil Engineering, Architecture, and Regional and City Planning), and regulators of the TOD concept. This research was conducted using a questionnaire consisting of open questions and questions with a likert scale. Data were analyzed using the one-sample t test method on likert scale questions to find out respondents 'understanding of the TOD concept and paired sample test methods to determine the consistency of respondents' understanding of open questions and likert scale questions. Based on the results of the study, it was found that student respondents had the lowest understanding of the TOD concept. While the academic respondents and regulator respondents have a fairly good understanding of the TOD concept.
\end{abstract}

Keywords: Transit; Oriented; Development; Public Transportation

\begin{abstract}
ABSTRAK
Masih banyak masyarakat yang lebih memilih untuk menggunakan kendaraan pribadi dibandingkan dengan transportasi umum. Salah satu cara mengurangi ketergantungan masyarakat terhadap penggunaan kendaraan bermotor pribadi dengan menerapkan konsep Transit Oriented Development (TOD). Tetapi penerapan konsep TOD yang ada saat ini masih ada yang kurang sesuai dengan konsep sesungguhnya sehingga manfaat dari konsep TOD tidak dapat dirasakan secara maksimal. Oleh karena itu, penelitian ini mencoba untuk meninjau tingkat pemahaman mahasiswa (Teknik Sipil, Arsitektur, dan Perencanaan Wilayah dan Kota), akademisi (Teknik Sipil, Arsitektur, dan Perencanaan Wilayah dan Kota), dan regulator terhadap konsep TOD. Penelitian ini dilakukan dengan menggunakan kuesioner yang terdiri dari pertanyaan terbuka dan pertanyaan dengan skala likert. Data dianalisis menggunakan metode one-sample $t$ test pada pertanyaan dengan skala likert untuk mengetahui pemahaman responden tentang konsep TOD dan metode paired sample test untuk mengetahui konsistensi pemahaman responden pada pertanyaan terbuka dan pertanyaan dengan skala likert. Berdasarkan hasil penelitian, didapatkan bahwa responden mahasiswa memiliki pemahaman tentang konsep TOD yang paling rendah. Sedangkan responden akademisi dan responden regulator memiliki pemahaman tentang konsep TOD yang cukup baik.
\end{abstract}

Kata kunci: Transit; Oriented; Development; Transportasi Publik

\section{PENDAHULUAN}

\section{Latar belakang}

Masih banyak masyarakat yang lebih memilih untuk menggunakan kendaraan pribadi dibandingkan dengan transportasi umum karena rute transportasi umum yang terbatas dan kurang fleksibel. Selain itu masih maraknya tindak kejahatan yang terjadi di transportasi umum yang membuat masyarakat memilih menggunakan kendaraan pribadi untuk rasa aman. Hal ini menyebabkan jumlah kendaraan melebihi kapasitas jalan menimbulkan kepadatan kendaraan yang menyebabkan kemacetan. Selain itu pola tata guna lahan yang tidak beraturan juga menimbulkan kepadatan akibat bangkitan perjalanan yang terjadi karena adanya aktivitas-aktivitas yang tidak dapat disediakan di kawasan tersebut. Maka diperlukan cara untuk mengurangi ketergantungan masyarakat terhadap penggunaan 
kendaraan pribadi. Salah satunya dengan menerapkan konsep Transit Oriented Development (TOD). Tujuan utama dari konsep TOD adalah mendorong masyarakat untuk menggunakan transportasi umum dibandingkan dengan kendaraan pribadi. Menurut Ewing et al (2017) TOD secara signifikan menciptakan permintaan parkir dan berkendara yang lebih rendah.

Tetapi dalam penerapan konsep TOD yang ada saat ini masih ada yang kurang sesuai dengan konsep aslinya sehingga manfaat dari konsep TOD tidak dapat dirasakan secara maksimal. Tidak semua transportasi umum menyediakan aksesbilitas yang terintegrasi antar satu transportasi umum dengan tranpostasi umum lainnya. Oleh karena itu, penelitian ini mencoba untuk meninjau tingkat pemahaman responden mahasiswa (Teknik Sipil, Arsitektur, dan Perencanaan Wilayah dan Kota), akademisi (Teknik Sipil, Arsitektur, dan Perencanaan Wilayah dan Kota), dan regulator terhadap konsep TOD karena pemahaman masing-masing responden sangat penting agar penerapan konsep TOD dapat diaplikasikan dengan benar.

Pemahaman masyarakat dan para pemangku kepentingan terhadap konsep Transit Oriented Development (TOD) masih kurang. Penerapan konsep TOD yang ada saat ini masih ada yang kurang sesuai dengan konsep aslinya. Diharapkan penerapan konsep TOD dapat diaplikasikan dengan benar sehingga manfaat dari TOD dapat dirasakan secara maksimal.

Persepsi pemahaman masyarakat dan para pemangku kepentingan terhadap konsep Transit Oriented Development dapat dicerminkan dalam pemahaman responden terhadap hal-hal yang mencakup berikut ini:

1. Definisi Transit Oriented Development

2. Ciri-ciri Transit Oriented Development

3. Manfaat Transit Oriented Development

\section{Transit Oriented Development (TOD)}

Seperti yang tertulis pada Permen ATR/KaBPN No. 16 Tahun 2017 tentang Pedoman Pengembangan Kawasan Berorientasi Transit Pengembangan Kawasan Berorientasi Transit atau Transit Oriented Development yang selanjutnya disingkat TOD adalah konsep pengembangan kawasan di dalam dan di sekitar simpul transit agar bernilai tambah yang menitikberatkan pada integrasi antar jaringan angkutan umum massal, dan antara jaringan angkutan umum massal dengan jaringan moda transportasi tidak bermotor, serta pengurangan penggunaan kendaraan bermotor yang disertai pengembangan kawasan campuran dan padat dengan intensitas pemanfaatan ruang sedang hingga tinggi.

Menurut Ewing et al (2017) TOD secara signifikan menciptakan permintaan parkir dan berkendara yang lebih rendah daripada melakukan pengembangan pinggiran kota yang konvensional. Menurut Pan et al (2017) beberapa implikasi untuk perencanaan TOD adalah perencanaan TOD harus terintegrasi dengan perencanaan jaringan transit kereta, lokasi stasiun harus berpasangan dengan pengembangan komersial, kepadatan pekerjaan yang tinggi harus didorong menjadi kunci masa depan TOD, dan stasiun perpindahan harus diposisikan lebih strategis dalam perencanaan jaringan transit kereta. Menurut Guthrie et al (2016) rekomendasi untuk mempromosikan TOD termasuk memperbaiki zoning dan pengembangan regulasi, rute bus yang lebih sering, kepastian yang lebih besar untuk transit dimasa depan, dan rekomendasi untuk mengintegrasikan TOD dengan pembangunan perumahan yang terjangkau.

\section{Pengalaman masyarakat dan perspektif para pemangku kepentingan terhadap TOD}

Menurut Noland et al (2017) di New Jesey, Amerika Serikat, terjadi peningkatan dukungan untuk TOD. Terdapat pertanyaan bagaimana persepsi masyarakat terhadap keuntungan dan kukurangan TOD dicegah dan ditambahkan oleh professional dalam perencanaan dan pengembangan TOD. Terdapat kesepakatan luas oleh penduduk dan profesional tentang nilai transit dan TOD untuk peningkatan aksesibilitas dan kemampuan berjalan. Masalah diidentifikasi dengan pengembangan ritel dan masalah lalu lintas. Dinyatakan sebagai masalah kemacetan oleh para profesional tetapi masalah keselamatan pejalan kaki oleh masyarakat. Informasi ini memberikan wawasan yang bermanfaat bagi para perencana dan pengembang yang ingin memberikan desain TOD yang sesuai dengan preferensi penduduk dan potensi penduduk.

Menurut Guthrie et al (2016) biaya tinggi dari aksesbilitas transit bisa mengurangi minat developer. Program subsidi atau pengurangan pajak di area stasiun bisa mengimbangi hambatan untuk TOD dan pengembangan ekonomi di area stasiun. Pengembang Twin Cities di Amerika Serikat melihat peraturan pengembangan (seperti zona sekali pakai, batas kepadatan terendah, tinggi parkir minimum) membatasi mereka mendapatkan keuntungan dekat tempat transit. Jika developer bisa membangun TOD yang sesungguhnya akan menyeimbangkan lapangan antara TOD dan area yang didominasi mobil yang akan meningkatkan kepadatan dan potensial keuntungan dalam investasi. Dengan 
mengurangi rasio minimum parkir dimana terdapat pilihan transit akan mengurangi biaya proyek TOD dan meningkatkan kepadatan penduduk dan destinasi di area stasiun.

\section{Dampak TOD terhadap lingkungan}

Menurut Kamruzzaman et al (2018) TOD diidentifikasikan sebagai alat perencanaan utama untuk mengatasi pengembangan yang tidak beraturan dan untuk mengatasi berbagai macam hasil yang tidak diinginkan. Pembangunan yang tidak beraturan telah diidentifikasi sebagai kunci faktor efek Urban Heat Island (UHI). Menggunakan kasus di Brisbane, Australia, didapatkan bahwa TOD mengalami efek UHI yang lebih tinggi dibandingkan dengan area non TOD. Keberagaman penggunaan lahan memberikan kontribusi secara signifikan terhadap efek UHI. Temuan menyarankan komproni diantara area alami dan buatan penting untuk mengurangi efek UHI selagi berkontribusi untuk tujuan utama TOD yaitu mendorong orang untuk berkendara lebih sedikit dan lebih banyak menggunakan angkutan umum.

Tinggal di kawasan TOD berarti orang cenderung lebih mengalami intensitas UHI yang lebih tinggi. Efek yang lebih langsung adalah penggunaan listrik yang lebih untuk pendinginan yang meningkatkan emisi gas rumah kaca. Oleh karena itu, untuk meciptakan kawasan TOD dengan konsep hijau harus dibuat dengan konsep bangunan yang sehat dan ramah lingkungan seperti atap dan dinding hijau yang bertindak sebagai isolasi, perangkat pendingin, dan mengurangi fluks panas melalui atap dan dinding. Dengan begitu bisa menghemat energi dan mengurani efek UHI.

The Center for Climate dan Energy Solutions (C2ES) menyatakan bahwa keseluruhan sistem transportasi memainkan peran penting dalam emisi gas rumah kaca. Kemacetan dapat digunakan sebagai contoh untuk kasus ini, yang disebabkan oleh permintaan melebihi kapasitas. Untuk mengurangi kemacetan, sederhananya dapat dilakukan dengan mengalihkan perjalaan dari kendaraan pribadi ke transportasi umum serta dengan menggunakan langkahlangkah manajemen lalu lintas. Mengurangi kemacetan memberi manfaat dalam menurunkan konsumsi bahan bakar dan emisi gas rumah kaca karena penurunan waktu berhenti dalam kemacetan. Dalam hal perubahan iklim, mengurangi emisi gas rumah kaca dari sektor transportasi akan membutuhkan pendekatan sistematis. Beberapa pendekatan sebagai proses mitigasi untuk mengurangi konsentrasi gas rumah kaca di atmosfer

\section{Mengganti fasilitas P\&R dengan TOD}

Banyak fasilitas Park and Ride (P\&R) disekitar stasiun utama di Amerika Serikat untuk meningkatkan penumpang angkutan tetapi belum jelas apakah bisa menyelesaikan tujuan berkelanjutan yang lebih luas. Dengan menggunakan lahan area stasiun yang langka untuk TOD daripada parkir akan menghasilkan pendekatan yang lebih baik untuk mengurangi Vehicle Kilometers Traveled (VKT).

Penelitian yang dilakukan oleh Duncan (2017) membandingkan P\&R dan TOD dalam mengurangi VKT. Survei dilakakukan di Charlotte, North Carolina, Amerika Serikat, digunakan untuk mengestimasi VKT yang dihasilkan oleh pengguna P\&R di stasiun kereta. Empat dari tujuh stasiun yang disurvei, dengan mengganti fasilitas P\&R dengan perumahan dengan kepadatan sedang diprediksi mengurangi VKT. Tetapi belum tentu dengan mengganti fasilitas parkir pinggir kota dengan TOD bisa mengurangi VKT.

Dalam kesimpulan jurnal ini, survei mengindikasikan tidak semua P\&R bisa dingantikan dengan TOD. P\&R yang kurang bermanfaat bisa menjadi kanditan yang bagus untuk penggantian menjadi TOD. Tetapi karena konsep P\&R bukan merupakan bagian dari TOD, maka pada penelitian ini tidak akan membahas lebih jauh tentang P\&R .

\section{METODE PENELITIAN}

Alur atau tahapan dari penelitian ini tertera dalam bentuk diagram seperti pada gambar 1 dibawah ini. 


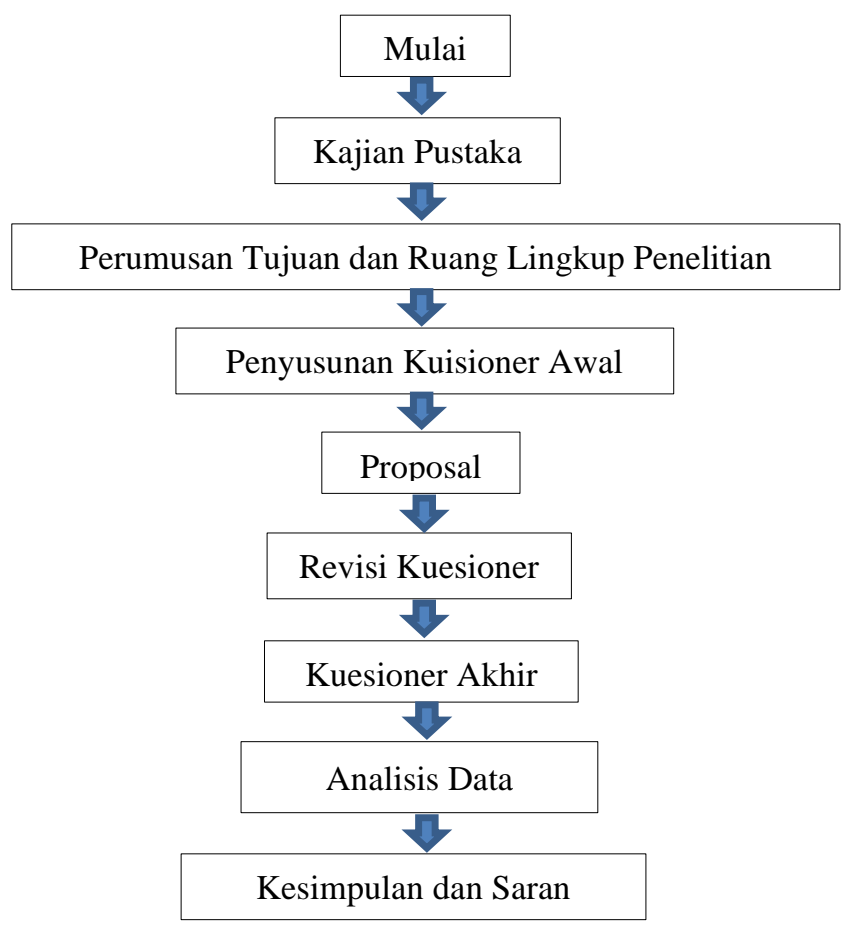

Gambar 1. Diagram alur penelitian

Subjek penelitian dalam penelitian ini merupakan mahasiswa (Teknik Sipil, Arsitektur, dan Perencanaan Wilayah dan Kota), akademisi (Teknik Sipil, Arsitektur, dan Perencanaan Wilayah dan Kota), dan regulator. Daftar pertanyaan pada kuesioner dibuat untuk memperoleh data-data primer yang disusun berdasarkan parameterparameter analisis yang dibutuhkan dan relevan sesuai dengan maksud dan tujuan dari penelitian ini sesuai responden yang sudah ditentukan sebelumnya.

Pengumpulan data dilakukan melalui kuesioner dengan pertanyaan yang berkaitan dengan tujuan dari penelitian ini. Pertanyaan tersebut didasari oleh aspek dan kriteria pada peneletian ini. Data yang diambil dari kuesioner ini adalah pemahaman masyarakat dan para pemangku kepentingan terhadap konsep TOD.

Aspek pada peneletian ini adalah

1. Pertanyaan terbuka:

- $\quad$ Kepanjangan TOD

- Makna transit dalam TOD

- Makna development dalam TOD

- Makna oriented dalam TOD

- Ciri-ciri TOD

- $\quad$ Manfaat TOD

2. Pertanyaan dengan skala likert:

- Makna transit

- Angkutan berbasis jalan

- Transit berbasis rel

- Kapasitas mengangkut penumpang

- Jarak berjalan kaki

- Pengembangan yang multi fungsi

- $\quad$ Fasilitas pejalan kaki 
- Akses pada siang hari

- Akses pada malam hari

- $\quad$ Program Bike Share

- Hubungan TOD dengan Urban Heat Island

- Hubungan TOD dengan emisi kendaraan bermotor

- Konsep bangunan di wilayah TOD

Kriteria pada peneletian ini adalah

1. Mahasiswa (Teknik Sipil, Arsitektur, dan Perencanaan Wilayah dan Kota) dengan SKS min. 100 dan IPK $\min .2 .75$

2. Akademisi (Teknik Sipil, Arsitektur, dan Perencanaan Wilayah dan Kota) yang berdomisili di Jabodetabek

3. Regulator.

\section{Kuesioner}

Dalam penelitian ini kuesioner disusun dengan menggunakan metode likert dan pertanyaan terbuka. Likert dibuat dalam skala frekuensi dan skala kesetujuan. Kuesioner dibuka dengan pertanyaan mengenai data responden. Setelah itu kuisioner dilanjutkan dengan pertanyaan-pertanyaan mengenai pemahaman mengenai TOD yang merupakan pertanyaan terbuka dan penilaian terkait dengan TOD. Kuisioner ini akan disebar dengan cara menemui responden secara langsung dan secara online melalui google form. Penilaian metode likert dapat dilihat pada Tabel 1.

Tabel 1. Penilaian metode likert

\begin{tabular}{|c|c|c|}
\hline \multicolumn{2}{|c|}{ Skala Likert } & Nilai \\
\hline \multirow{4}{*}{ Likert Kesetujuan } & Sangat Tidak Setuju & 1 \\
\hline & Tidak Setuju & 2 \\
\hline & Setuju & 3 \\
\hline & Sangat Setuju & 4 \\
\hline
\end{tabular}

\section{Targer kuesioner}

Target penelitian ini adalah mengumpulkan minimal 100 responden mahasiswa (Teknik Sipil, Arsitektur, dan Perencanaan Wilayah dan Kota) dengan pembagian 45 responden mahasiwa Teknik Sipil, 35 responden mahasiswa Arsitektur, dan 20 responden mahasiswa Perencanaan Wilayah dan Kota. Responden akademisi (Teknik Sipil, Arsitektur, dan Perencanaan Wilayah dan Kota) yang berdomisili di Jabodetabek minimal 10 orang dan responden regulator minimal 10 orang.

\section{Metode dan teknik analisis data}

Pada penelitian ini pengolahan data menggunakan program IBM SPSS Statistics versi 25. Data yang telah didapatkan dari menyebarkan kuisioner secara langsung dan secara online akan dikelompokan berdasarkan kriteria yang telah ditentukan pada penelitian ini dan data akan dianalisis menggunakan program SPSS. Pada jawaban pertanyaan dengan skala likert, data akan dianalisis dengan metode one-sample t test untuk mendapatkan hasil pemahaman responden terhadap pertanyaan-pertanyaan pada kuesioner. Sedangkan jawaban pertanyaan terbuka akan dinilai dan dikonversi dalam bentuk angka sehingga jawaban pertanyaan terbuka dapat dibandingkan dengan jawaban skala likert dengan menggunakan metode analisis paired-sample test. Hasil perbandingan diuji dengan menggunakan metode analisis paired-sample test untuk menguji konsistensi jawaban responden dalam menjawab pertanyaan terbuka dan pertanyaan dengan skala likert.

\section{HASIL DAN PEMBAHASAN}

Pada awal perencanaan penelitian, jumlah responden yang direncanakan berjumlah 100 orang mahasiswa (Teknik Sipil, Arsitektur, dan Perencanaan Wilayah dan Kota), 10 orang akademisi (Teknik Sipil, Arsitektur, dan Perencanaan Wilayah dan Kota), dan 10 orang regulator. Kuesioner dapat diisi secara langusung maupun secara 
online dimana pada pembagian kuesioner secara langsung didapatkan 70 orang mahasiswa dan 9 orang akademisi. Sedangkan pada pembagian kuesioner secara online didapatkan 30 orang mahasiswa, 1 orang akademisi, dan 10 orang regulator. Seluruh responden regulator mengisi kuesioner secara online karena adanya keterbatasan akses dan waktu.

Data-data responden yang terdapat dalam kuesioner adalah data umum berupa jenis kelamin responden, usia responden, program studi responden bagi responden mahasiswa atau akademisi, dan profesi responden bagi responden regulator. Data umum responden dapat dilihat pada Tabel 2 hingga Tabel 5

Tabel 2. Data jenis kelamin dan usia responden mahasiswa

\begin{tabular}{lcr}
\hline Jenis Kelamin & Usia & Jumlah \\
\hline Laki-Laki & 20-30 Tahun & 71 \\
Perempuan & 20-30 Tahun & 29 \\
& Total & 100 \\
\hline
\end{tabular}

Tabel 3. Data jenis kelamin dan usia responden akademisi

\begin{tabular}{clr}
\hline Jenis Kelamin & \multicolumn{1}{c}{ Usia } & Jumlah \\
\hline \multirow{4}{*}{ Laki-Laki } & 20-30 Tahun & - \\
\cline { 2 - 3 } & 30-50 Tahun & 1 \\
\cline { 2 - 3 } Perempuan & 20-30 Tahun \\
\cline { 2 - 3 } & 30-50 Tahun & 1 \\
\cline { 2 - 3 } & $>50$ Tahun & 2 \\
\hline
\end{tabular}

Tabel 4. Data jenis kelamin dan usia responden regulator

\begin{tabular}{clr}
\hline Jenis Kelamin & \multicolumn{1}{c}{ Usia } & Jumlah \\
\hline \multirow{3}{*}{ Laki-Laki } & 20-30 Tahun & 1 \\
\cline { 2 - 3 } & 30-50 Tahun & 6 \\
\cline { 2 - 3 } & >50 Tahun & 3 \\
\hline \multirow{3}{*}{ Perempuan } & 20-30 Tahun & - \\
\cline { 2 - 3 } & 30-50 Tahun & - \\
\cline { 2 - 3 } & $>50$ Tahun & - \\
\hline & Total & 10 \\
\hline
\end{tabular}

Untuk responden regulator didapatkan 10 responden dan seluruh responden mengisi kuesioner secara online karena adanya keterbatasan akses dan waktu. Profesi responden seputar lingkup Kementrian Perhubungan di tingkat pusat maupun di tingkat daerah, Kementrian Perkerjaan Umum dan Perumahan Rakyat di tingkat pusat maupun di tingkat daerah, dan Dinas Perhubungan Daerah.

\section{Pembahasan khusus pada pertanyaan nomor 2 "pada umumnya transit merupakan angkutan berbasis jalan" pada pertanyaan dengan skala likert}

Pada pertanyaan nomor 2 dalam pertanyaan dengan skala likert, yaitu "Pada umumnya transit merupakan angkutan berbasis jalan" akan dibahas secara khusus pada bab ini. Sebernarnya pada umumnya transit pada konsep TOD merupakan angkutan berbasis rel karena angkutan berbasis rel merupakan angkutan yang paling cocok dengan konsep TOD. Angkutan berbasis rel dapat mengangkut penumpang dalam kapasitas besar dan memiliki waktu tempuh yang cepat sehingga dapat meningkatkan mobilitas pada kawasan tersebut. Contoh angkutan berbasi rel adalah MRT. 
Pada pertanyaan nomor 2, pertanyaan dibuat dengan konteks ke arah negatif untuk menguji pemahaman responden tentang konsep transit pada TOD. Karena konteks pertanyaan ke arah negatif maka skala yang seharusnya diberikan pada pertanyaan ini menggunakan skala 1 sampai 4 dari sangat tidak setuju sampai sangat setuju diubah menjadi menggunakan skala 4 sampai 1 dari sangat setuju sampai sangat tidak setuju. Secara umum hasil jawaban responden pada pertanyaan ini cenderung setuju dengan pertanyaan "Pada umumnya transit merupakan angkutan berbasis jalan". Hal ini menunjukan bahwa responden cenderung tidak memahami konsep transit pada TOD dengan benar.

Tetapi angkutan berbasis jalan dapat dikatakan termasuk dalam bagian TOD jika angkutan tersebut merupakan Bus Rapit Transit (BRT). Yang termasuk dalam BRT adalah Bus Transjakarta. Angkutan berbasis jalan selain BRT tidak termasuk dalam bagian TOD. Hasil jawaban responden cenderung setuju dengan pertanyaan "Pada umumnya transit merupakan angkutan berbasis jalan" bisa dikarenakan konteks pertanyaan ke arah negatif menyebabkan munculnya kebingungan responden apakah angkutan berbasis jalan atau angkutan berbasis rel yang termasuk dalam konsep TOD. Muncul juga kebingungan dalam membedakan angkutan berbasis jalan yang termasuk dalam bagian TOD.

\section{Metode analisis One-Sample T Test pada pertanyaan dengan skala likert}

Pada pertanyaan dengan skala likert, hasil jawaban responden akan dianalisis dengan menggunakan metode OneSample $T$ Test untuk mendapatkan hasil pemahaman responden terhadap konsep TOD. Setiap pertanyaan menggunakan skala 1-4 dimana menjelaskan angka 1 (sangat tidak setuju), angka 2 (tidak setuju), angka 3 (setuju), dan angka 4 (sangat setuju). Tetapi pada pertanyaan yang memiliki konteks pertanyaan ke arah negatif skala diubah menjadi menggunakan skala 4-1 dari sangat setuju-sangat tidak setuju.

\section{Hasil analisis pertanyaan dengan skala likert terhadap 100 mahasiswa (teknik sipil, arsitektur, dan perencanaan wilayah dan kota)}

Secara umum kelompok responden mahasiswa (Teknik Sipil, Arsitektur, dan Perencanaan Wilayah dan Kota) dapat memahami dan menjawab pertanyaan tentang konsep TOD dengan skala likert dengan benar. Dapat dilihat dari nilai selisih mean cenderung bernilai positif menunjukan bahwa responden memahami konsep TOD. Tetapi pada pertanyaan nomor 2 dan 16, didapat bahwa nilai selisih mean bernilai negatif. Hal ini menunjukan bahwa kelompok responden mahasiswa kurang memahami konsep TOD yang diwakili pertanyaan nomor 2 (nilai selisih mean -0,3) dan 16 (nilai selisih mean -0,14) karena respoden cenderung tidak menjawab pertanyaan dengan benar.

Pada pertanyaan nomor 2 "Pada umumnya transit merupakan angkutan berbasis jalan", lebih banyak responden yang setuju daripada responden yang tidak setuju dengan pertanyaan nomor 2. Hal ini ditunjukan oleh nilai mean pertanyaan nomor 2 kurang dari $2,5(2,2 \leq 2,5)$. Karena pada umumnya transit merupakan angkutan berbasis rel. Pertanyaan nomor 2 mewakili konsep TOD terkait dengan transit.

Sama halnya pada pertanyaan nomor 16 "TOD dapat meningkatkan urban heat island", nilai mean kurang dari 2,5 $(2,36 \leq 2,5)$. TOD dapat mengurangi urban heat island karena mengurangi penggunaan bahan bakar yang dapat mengurangi polusi dan mengurangi suhu perkotaan. Pertanyaan nomor 16 mewakili konsep TOD terkait dengan manfaat TOD. Hasil one-sample $t$ test 100 mahasiswa dapat dilihat pada Tabel 5.

Tabel 5. Hasil one-sample $t$ test 100 mahasiswa

\begin{tabular}{ccccc}
\hline Pertanyaan & Mean & $\begin{array}{c}\text { Selisih } \\
\text { Mean }\end{array}$ & $\alpha$ & $\begin{array}{c}\text { Signifikan } \\
\text { Pada } \alpha \leq 0,05 \\
\text { (Ya/Tidak) }\end{array}$ \\
\hline 1 & 3,330 & 0,830 & 0,000 & Ya \\
\hline 2 & 2,200 & $-0,300$ & 0,000 & Ya \\
\hline 3 & 3,560 & 1,060 & 0,000 & Ya \\
\hline 4 & 2,910 & 0,410 & 0,000 & Ya \\
\hline 5 & 3,520 & 1,020 & 0,000 & Ya \\
\hline 7 & 2,610 & 0,110 & 0,193 & Tidak \\
\hline 8 & 3,670 & 1,170 & 0,000 & Ya \\
\hline 9 & 2,690 & 0,190 & 0,008 & Ya \\
\hline 10 & 2,600 & 0,100 & 0,263 & Tidak \\
\hline 11 & 3,470 & 0,970 & 0,000 & Ya \\
\hline & 3,500 & 1,000 & 0,000 & Ya
\end{tabular}


Tabel 5. Hasil one-sample t test 100 mahasiswa (Lanjutan)

\begin{tabular}{ccccc}
\hline Pertanyaan & Mean & $\begin{array}{r}\text { Selisih } \\
\text { Mean }\end{array}$ & $\alpha$ & $\begin{array}{c}\text { Signifikan } \\
\text { Pada } \alpha \leq 0,05 \\
\text { Ya/Tidak) }\end{array}$ \\
\hline 12 & 2,880 & 0,380 & 0,000 & Ya \\
\hline 13 & 2,850 & 0,350 & 0,000 & Ya \\
\hline 14 & 3,850 & 1,350 & 0,000 & Ya \\
\hline 15 & 3,560 & 1,060 & 0,000 & Ya \\
\hline 16 & 2,360 & $-0,140$ & 0,073 & Tidak \\
\hline 17 & 3,590 & 1,090 & 0,000 & Ya \\
\hline 18 & 3,630 & 1,130 & 0,000 & Ya \\
\hline
\end{tabular}

\section{Hasil analisis pertanyaan dengan skala likert terhadap responden akademisi}

Responden akademisi dapat memahami dan menjawab pertanyaan tentang konsep TOD dengan skala likert dengan benar. Dapat dilihat dari seluruh nilai selisih mean cenderung bernilai positif menunjukan bahwa responden memahami konsep TOD. Tabel 6. Hasil one-sample t test akademisi dapat dilihat pada Tabel 6.

Tabel 6. Hasil one-sample $t$ test akademisi

\begin{tabular}{|c|c|c|c|c|}
\hline Pertanyaan & Mean & $\begin{array}{l}\text { Selisih } \\
\text { Mean }\end{array}$ & $\alpha$ & $\begin{array}{c}\text { Signifikan } \\
\text { Pada } \alpha \leq 0,05 \\
\text { (Ya/Tidak) }\end{array}$ \\
\hline 1 & 3,900 & 1,400 & 0,000 & $\mathrm{Ya}$ \\
\hline 2 & 3,100 & 0,600 & 0,030 & $\mathrm{Ya}$ \\
\hline 3 & 3,900 & 1,400 & 0,000 & $\mathrm{Ya}$ \\
\hline 4 & 3,800 & 1,300 & 0,000 & $\mathrm{Ya}$ \\
\hline 5 & 3,800 & 1,300 & 0,000 & $\mathrm{Ya}$ \\
\hline 6 & 3,400 & 0,900 & 0,008 & Tidak \\
\hline 7 & 3,800 & 1,300 & 0,000 & $\mathrm{Ya}$ \\
\hline 8 & 3,700 & 1,200 & 0,000 & $\mathrm{Ya}$ \\
\hline 9 & 3,200 & 0,700 & 0,061 & Tidak \\
\hline 10 & 3,700 & 1,200 & 0,000 & $\mathrm{Ya}$ \\
\hline 11 & 3,900 & 1,400 & 0,000 & $\mathrm{Ya}$ \\
\hline 12 & 3,500 & 1,000 & 0,000 & $\mathrm{Ya}$ \\
\hline 13 & 3,500 & 1,000 & 0,000 & $\mathrm{Ya}$ \\
\hline 14 & 3,900 & 1,400 & 0,000 & $\mathrm{Ya}$ \\
\hline 15 & 3,900 & 1,400 & 0,000 & $\mathrm{Ya}$ \\
\hline 16 & 3,500 & 1,000 & 0,000 & Tidak \\
\hline 17 & 3,900 & 1,400 & 0,000 & $\mathrm{Ya}$ \\
\hline 18 & 3,900 & 1,400 & 0,000 & $\mathrm{Ya}$ \\
\hline
\end{tabular}

\section{Hasil analisis pertanyaan dengan skala likert terhadap responden regulator}

Responden regulator dapat memahami dan menjawab pertanyaan tentang konsep TOD dengan skala likert dengan benar. Dapat dilihat dari seluruh nilai selisih mean cenderung bernilai positif menunjukan bahwa responden memahami konsep TOD. Hasil one-sample t test regulator dapat dilihat pada Tabel 7. 
Tabel 7. Hasil one-sample $t$ test regulator

\begin{tabular}{|c|c|c|c|c|}
\hline Pertanyaan & Mean & $\begin{array}{l}\text { Selisih } \\
\text { Mean }\end{array}$ & $\alpha$ & $\begin{array}{c}\text { Signifikan } \\
\text { Pada } \alpha \leq 0,05 \\
\text { (Ya/Tidak) }\end{array}$ \\
\hline 1 & 3,400 & 0,900 & 0,003 & $\mathrm{Ya}$ \\
\hline 2 & 3,100 & 0,600 & 0,030 & $\mathrm{Ya}$ \\
\hline 3 & 3,800 & 1,300 & 0,000 & $\mathrm{Ya}$ \\
\hline 4 & 3,600 & 1,100 & 0,001 & $\mathrm{Ya}$ \\
\hline 5 & 3,800 & 1,300 & 0,000 & $\mathrm{Ya}$ \\
\hline 6 & 2,900 & 0,400 & 0,121 & Tidak \\
\hline 7 & 3,900 & 1,400 & 0,000 & $\mathrm{Ya}$ \\
\hline 8 & 3,600 & 1,100 & 0,001 & $\mathrm{Ya}$ \\
\hline 9 & 3,200 & 0,700 & 0,021 & $\mathrm{Ya}$ \\
\hline 10 & 3,600 & 1,100 & 0,000 & $\mathrm{Ya}$ \\
\hline 11 & 3,800 & 1,300 & 0,000 & $\mathrm{Ya}$ \\
\hline 12 & 3,500 & 1,000 & 0,002 & $\mathrm{Ya}$ \\
\hline 13 & 2,900 & 0,400 & 0,053 & Tidak \\
\hline 14 & 3,900 & 1,400 & 0,000 & $\mathrm{Ya}$ \\
\hline 15 & 3,700 & 1,200 & 0,000 & $\mathrm{Ya}$ \\
\hline 16 & 3,200 & 0,700 & 0,061 & Tidak \\
\hline 17 & 3,900 & 1,400 & 0,000 & $\mathrm{Ya}$ \\
\hline 18 & 3,900 & 1,400 & 0,000 & $\mathrm{Ya}$ \\
\hline
\end{tabular}

\section{KESIMPULAN DAN SARAN}

\section{Kesimpulan}

Berdasarkan penelitian yang telah dilakukan dapat disimpulkan sebagai berikut:

1. Responden mahasiswa kurang memahami konsep TOD dengan skala likert yang diwakili pertanyaan nomor 2 "Pada umumnya transit merupakan angkutan berbasis jalan" yang mewakili konsep TOD terkait dengan transit dan 16 "TOD dapat meningkatkan urban heat island" yang mewakili konsep TOD terkait dengan manfaat TOD. Hal ini ditunjukan dengan nilai selisih mean bernilai negatif yang menunjukan respoden cenderung tidak menjawab pertanyaan dengan benar.

2. Responden akademisi dan regulator dapat memahami dan menjawab pertanyaan tentang konsep TOD dengan skala likert dengan benar. Dilihat dari seluruh nilai selisih mean bernilai positif yang menunjukan bahwa responden memahami konsep TOD.

\section{Saran pemanfaatan penelitian}

Berdasarkan penelitian dan penarikan kesimpulan yang telah dilakukan dapat direkomendasikan saran terhadap pemanfaatan penelitian ini, yakni:

1. Penelitian ini dapat digunakan sebagai dasar pertimbangan khususnya untuk program studi Teknik Sipil agar dapat membahas dan mempelajari tentang konsep TOD lebih mendalam untuk memperkuat pemahaman mahasiswa Teknik Sipil terhadap konsep TOD.

2. Diperlukan adanya workshop tentang konsep TOD khususnya untuk responden mahasiswa karena pada penelitian ini didapatkan bahwa masih terdapat pemahaman mahasiswa yang salah terhadap konsep TOD. Sehingga setelah mahasiswa menyelesaikan perkuliahan dan masuk ke dalam dunia kerja tidak terjadi kesalahan dalam merealisasikan konsep TOD.

\section{Saran terhadap penelitian selanjutnya}

Berdasarkan penelitian yang sudah dilakukan dapat direkomendasikan saran terhadap penelitian selanjutnya, yakni: 
Karena keterbatasan waktu dan akses maka responden mahasiswa pada penelitian ini hanya berada di dalam lingkup Universitas Tarumanagara. Sehingga dalam penelitian selanjutnya, untuk mendapatkan pemahaman mahasiswa dan akademisi tentang konsep TOD yang lebih luas responden mahasiswa dan akademisi dapat dicari mencakup universitas-universitas lainnya.

\section{DAFTAR PUSTAKA}

Center for Climate and Energy Solutions. Energy Use Transportation, https://www.c2es.org/2016/06/transportationemissions-roll-over-power-sector-emissions/, (Diakses pada tanggal 2 Januari 2019)

Duncan, Michael. "Would the replacement of park-and-ride facilities with transit-oriented development reduce vehicle kilometers traveled in an auto-oriented US region." Transport Policy, vol. 81, 2017, pp. 293-301.

Ewing, Reid, et al. "Trip and parking generation at transit-oriented developments: Five US case studies.” Lanscape and Urban Planning, vol. 160, 2017, pp. 69-78.

Guthrie, Andrew,et al. "Developers' perspectives on transit-oriented development." Transport Policy, vol. 51, 2016, pp. 103-114.

Kamruzzaman, Md, et al. "Investigating the urban heat island effect of transit oriented development in Brisbane." Journal of Transport Geography, vol. 66, 2018, pp. 116-124.

Kementrian Perhubungan Sekretariat Jendral Satuan Kerja Biro Perencanaan. Penyusun Rencana Induk Transportasi Nasional Tahun Anggaran 2019. 2019, Jakarta

Noland, R.B, et al. "Attitudes towards transit-oriented development-Resident experiences and professional perspectives.” Journal of Transport Geography, vol. 60, 2017, pp. 130-140.

Pan, Haixiao, et al. "What determines rail transit passenger volume Implications for transit oriented development planning." Transportation Research Part D, vol. 57, 2017, pp. 52-63.

Peraturan Menteri Agraria dan Tata Ruang/Kepala Badan Pertahanan Nasional Republik Indonesia Nomor 16 Tahun 2017 tentang Pedoman Pengembangan Kawasan Berorientasi Transit atau Transit Oriented Development 